\title{
The role of surface-subsurface interactions in the distributed hydrological response of a headwater-dominated catchment
}

\author{
Ilhan Özgen Xian ${ }^{1}$, Sergi Molins ${ }^{1}$, Rachel M. Johnson ${ }^{1}$, Ralf Loritz ${ }^{2}$, Zexuan Xu ${ }^{1}$, \\ Dipankar Dwivedi ${ }^{1}$, Utkarsh Mital $^{1}$, Craig Ulrich ${ }^{1}$, and Carl Steefel ${ }^{1}$ \\ ${ }^{1}$ E O Lawrence Berkeley National Laboratory \\ ${ }^{2}$ Institute of Water and River Basin Management Karlsruhe Institute of Technology \\ Germany
}

February 28, 2022

\begin{abstract}
We numerically study how the interactions between surface, subsurface, and rainfall create complex runoff behavior in a headwater-dominated high elevation, mountainous catchment in East River Watershed, Colorado, USA. In order to understand the effect of surface-subsurface interactions on the hydrological response, we compare model variations with different soil permeability. We compute hydrographs, hydrological indices, and spatio-temporal distributions of hydrological variables. The indices and distributions are then linked to the hydrograph at the outlet of the domain. Our results show that changing surface-subsurface interactions trigger different flow regimes, connectivity dynamics, and runoff generation mechanisms inside the catchment, and hence, affect the distributed hydrological response. Increased surface-subsurface interaction leads to a higher degree of connectivity in the catchment. Temporal dynamics of both distributed and aggregated hydrological response did not change significantly, which may be because the structural connectivity of the catchment remained untouched. Our results indicate that in higher order catchments, the effect of changes in distributed hydrological response may not always be observable through aggregated hydrological signatures.
\end{abstract}

\section{Hosted file}

main.pdf available at https://authorea.com/users/462785/articles/558109-the-role-ofsurface-subsurface-interactions-in-the-distributed-hydrological-response-of-a-headwaterdominated-catchment 

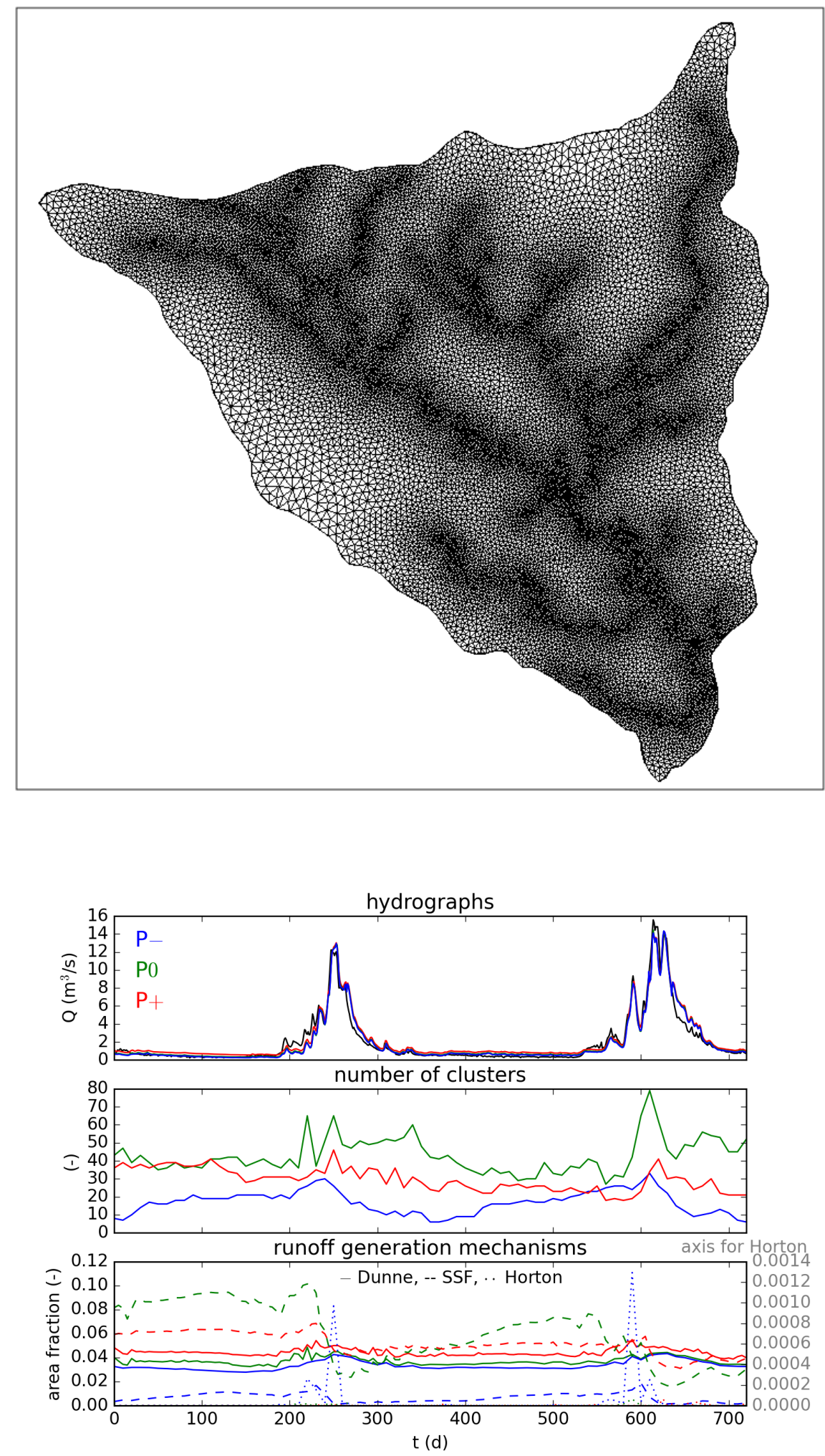

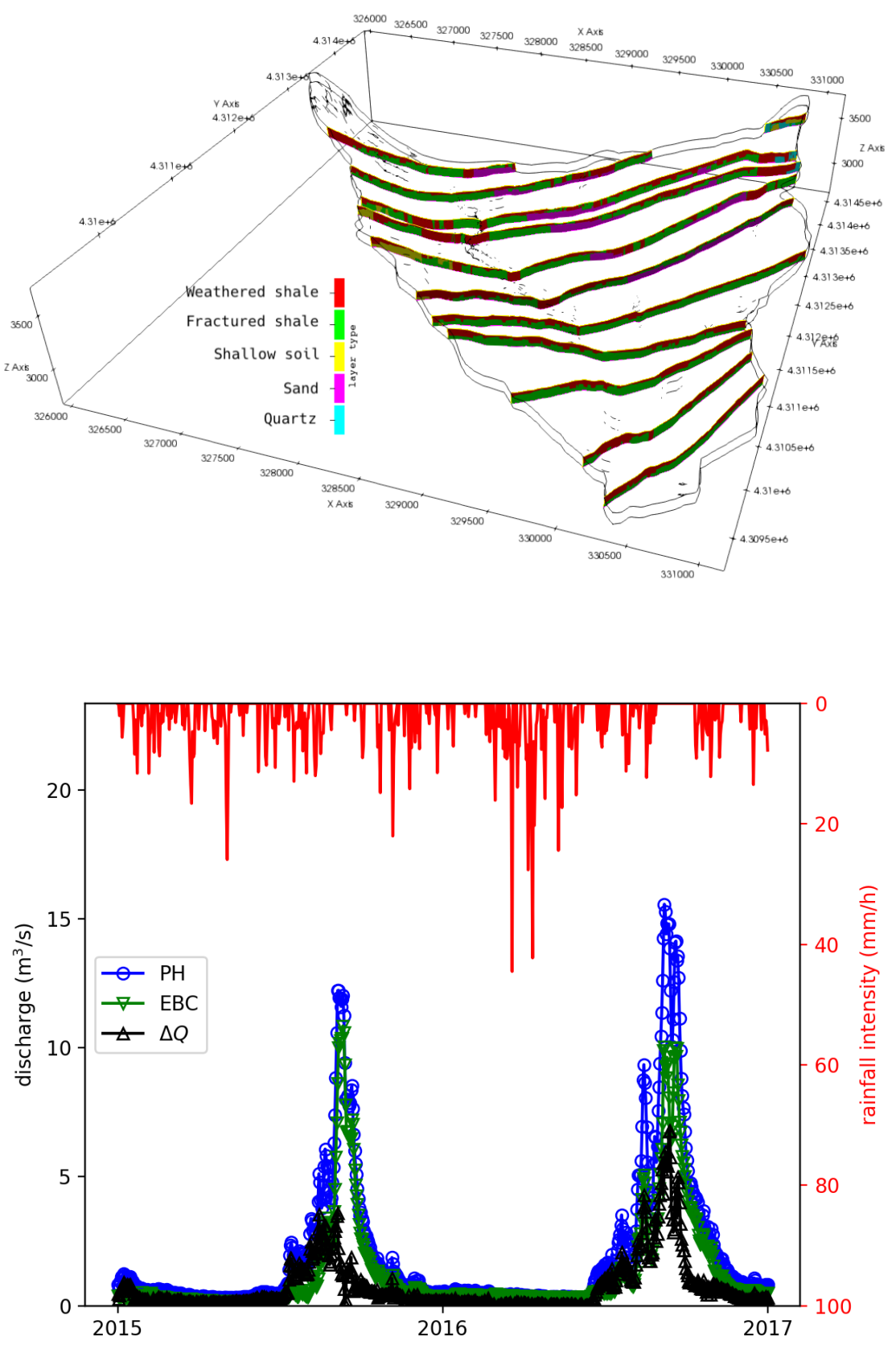


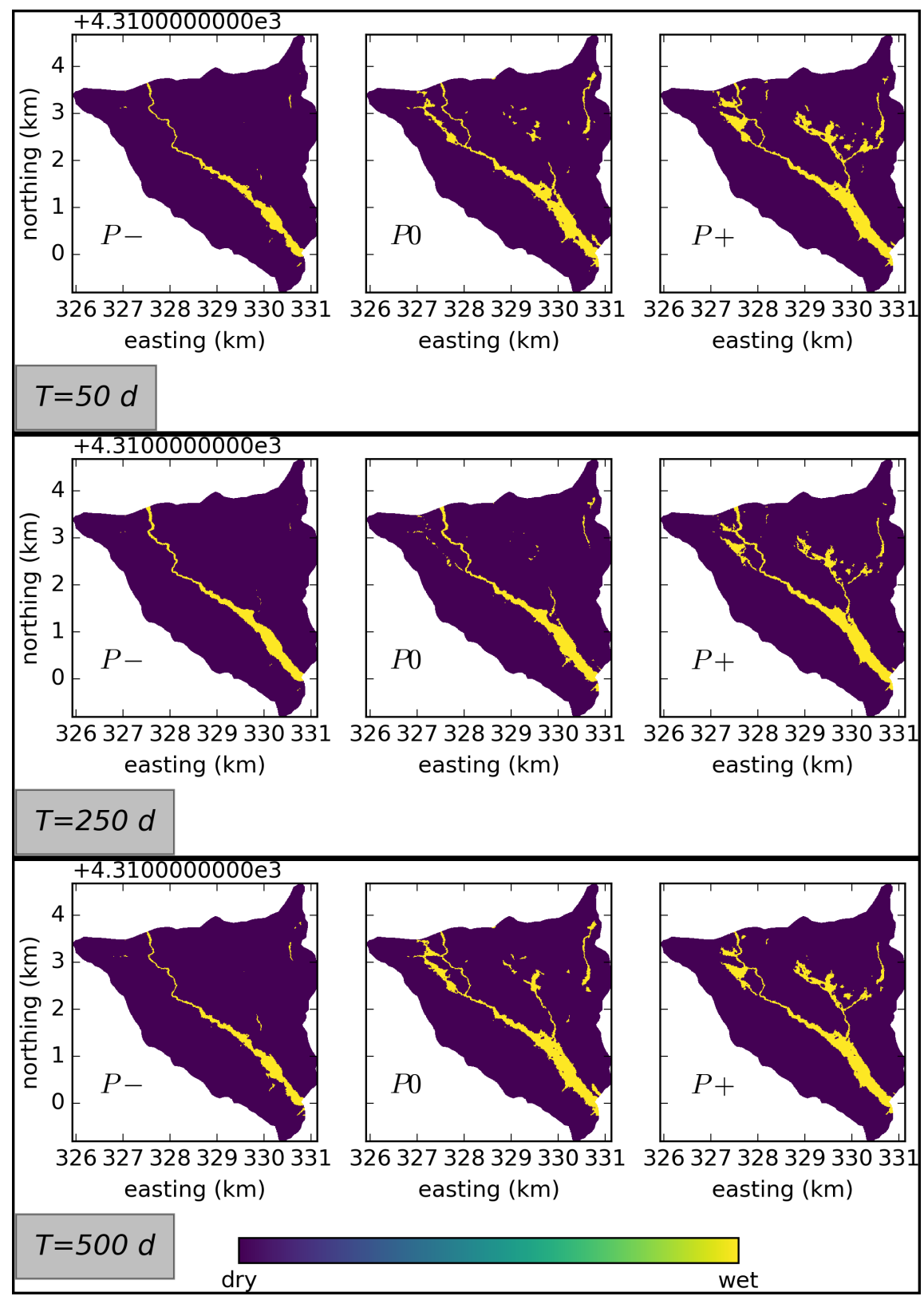



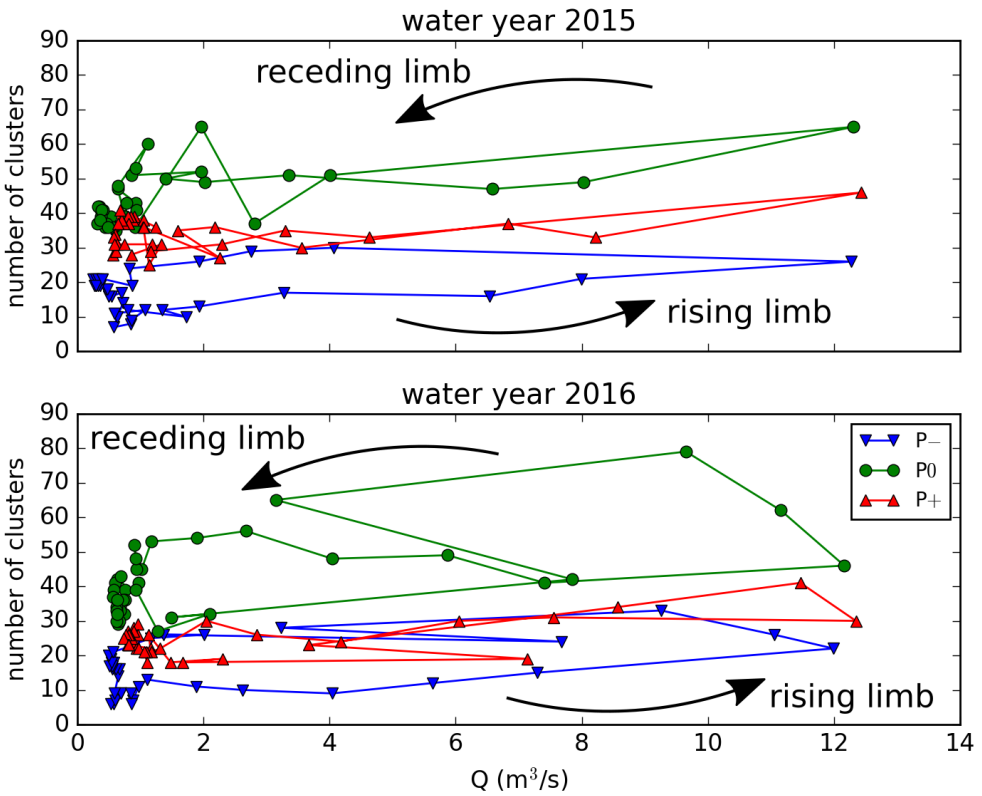


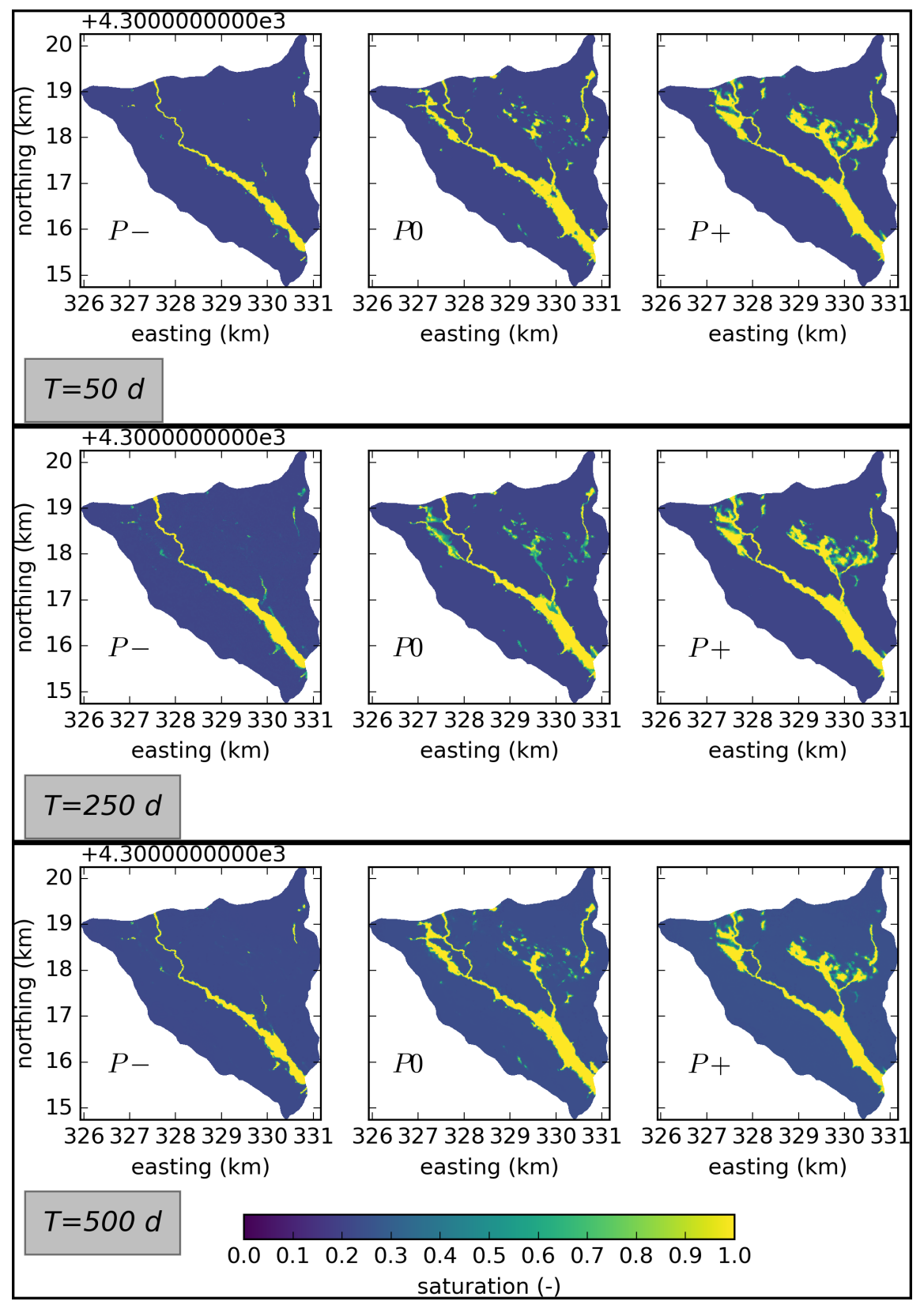



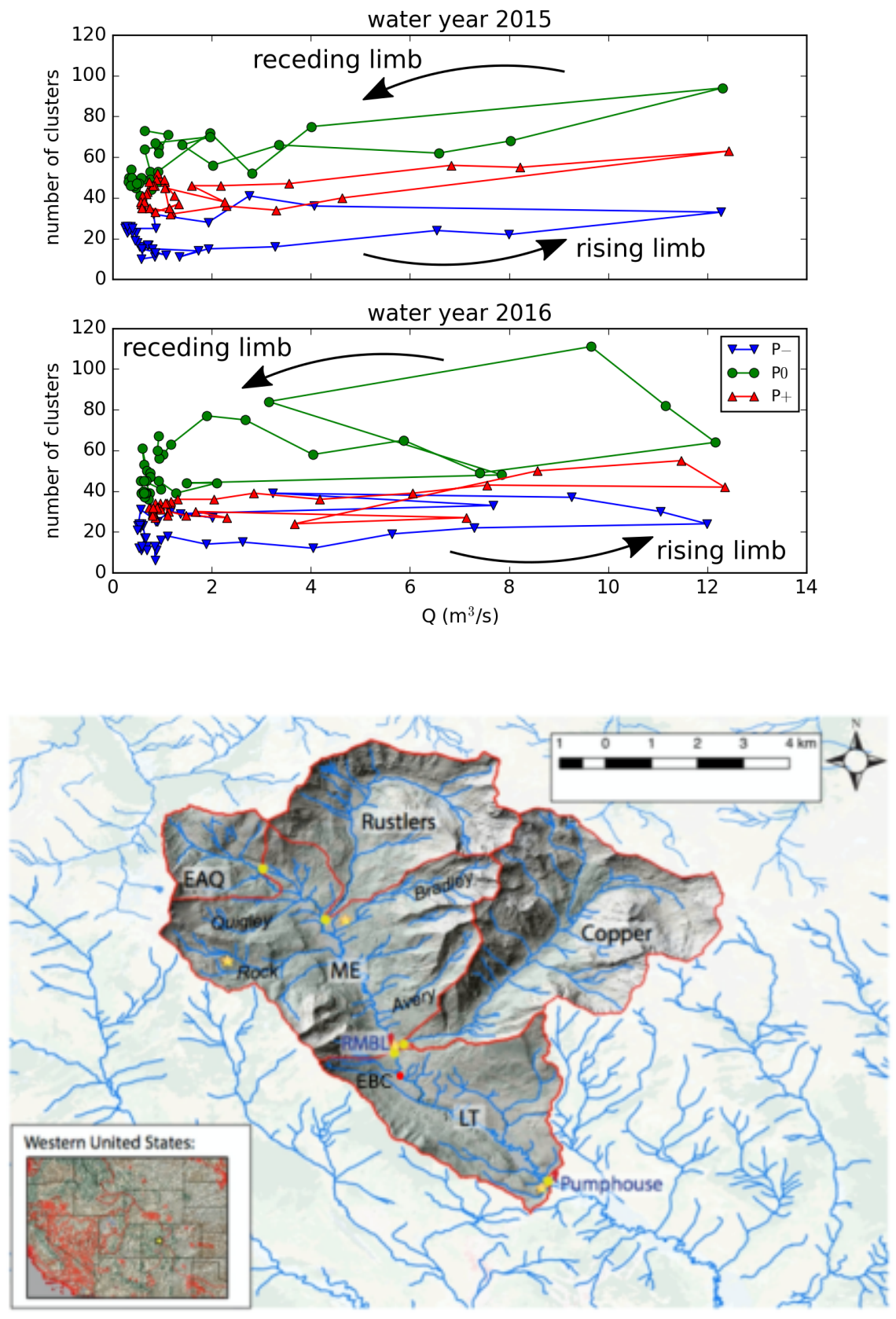


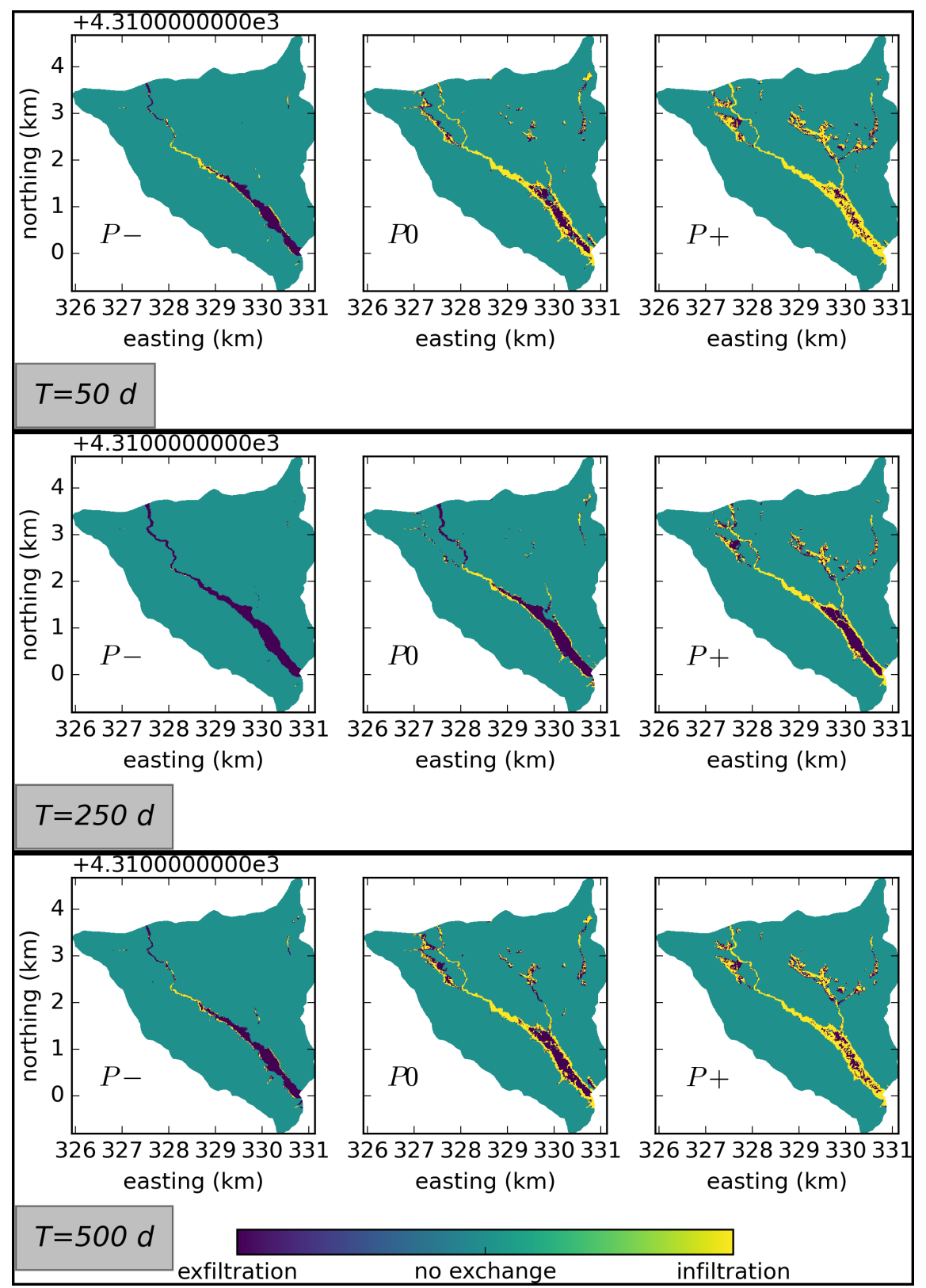

